\title{
Correction to: Per Aqueous Liquid Chromatography (PALC) as a Simple Method for Native Separation of Protein A
}

\author{
Garshasb Rigi ${ }^{1}$ Mohsen Farhadpour ${ }^{2}$ - Alireza Ghasempour ${ }^{2}$. \\ Gholamreza Ahmadian ${ }^{3} \cdot$ Hassan Y. Aboul-Enein ${ }^{4}$
}

Published online: 4 November 2017

(c) Springer-Verlag GmbH Germany 2017

\section{Correction to: Chromatographia \\ DOI 10.1007/s10337-017-3412-1}

Please correct the sequence of the authors to read as follows:

Garshasb Rigi ${ }^{1}$, Mohsen Farhadpour ${ }^{2}$, Alireza Ghasempour $^{2^{*}}$, Gholamreza Ahmadian ${ }^{3 *}$ and Hassan Y. Aboul-Enein ${ }^{4}$

${ }^{\#}$ Garshasb Rigi and Mohsen Farhadpour are joint first authors.

${ }^{1}$ Department of Genetics, Faculty of Basic Sciences, University of Shahrekord, Shahrekord, Iran

Garshasb Rigi and Mohsen Farhadpour are joint first authors.

The online version of the original article can be found under https://doi.org/10.1007/s10337-017-3412-1.

Alireza Ghasempour

a-ghassempour@sbu.ac.ir

$\triangle$ Gholamreza Ahmadian

ahmadian@nigeb.ac.ir

Hassan Y. Aboul-Enein

haboulenein@yahoo.com

1 Department of Genetics, Faculty of Basic Sciences, University of Shahrekord, Shahrekord, Iran

2 Department of Phytochemistry, Medicinal Plants and Drugs Research Institute, Shahid Beheshti University, G.C., Evin, Tehran, Iran

3 Department of Industrial and Environmental Biotechnology, National Institute of Genetic Engineering and Biotechnology (NIGEB), P.O. Box 14155-6343, Tehran, Iran

4 Pharmaceutical and Medicinal Chemistry Department, Pharmaceutical and Drug Industries Research Division, National Research Center, Dokki, Cairo 12622, Egypt
${ }^{2}$ Department of Phytochemistry, Medicinal Plants and Drugs Research Institute, Shahid Beheshti University, G.C., Evin, Tehran, Iran

${ }^{3}$ Department of Industrial and Environmental Biotechnology, National Institute of Genetic Engineering and Biotechnology (NIGEB), P.O. Box 14155-6343, Tehran, Iran

${ }^{4}$ Pharmaceutical and Medicinal Chemistry Department, Pharmaceutical and Drug Industries Research Division, National Research Center, Dokki, Cairo 12622, Egypt

* Alireza Ghasempour

a-ghassempour@sbu.ac.ir

* Gholamreza Ahmadian

ahmadian@nigeb.ac.ir 